\title{
Optimalisasi Penentuan Supplier dengan Pendekatan Metode AHP
}

Oleh

\author{
: Alam Supriyatna
}

\begin{abstract}
Abstrak
Diera kompetisi saat ini menuntut para pelaku dunia usaha untuk lebih cermat dalam pengambilan keputasan agar dapat bersaing dan menjaga kesinambungan bisnis yang ditekuni. Dalam setiap tahapan proses bisnis banyak hal yang harhus dicermati, diantaranya adalah bagaimana cara meningkatkan efisiensi, efektifitas dan daya saing, salah satu dari tahapan proses bisnis adalah menentukan pemasok /Supplier. Analytical Hierarchy Process (AHP) merupakan sebuah kerangka untuk pengamengambianl keputusan yang efektif dengan menyederhanakan dan mempercepat proses pengambilan keputusan. AHP menata bagian-bagian atau variabel kedalam susunan hirarki, memberi nilai numerik pada perhitungan subjektif, menjelaskan tentang pentingnya tiap variabel dan mensintesiskan berbagai pertimbangan, untuk menetapkan variabel yang mana memiliki prioritas paling tinggi dan bertindak untuk mempengaruhi hasil pada situasi tersebut. AHP dapat menyederhanakan masalah yang kompleks dan tidak terstruktur, dengan strategi menjadikan variabel dalam suatu hirarki. Pada penelitian yang bertujuan untuk optimalisasi penentuan supplier ini dapat ditarik kesimpulan, berdasarkan hasil analisa AHP dan berdasarkan hasil penelitian yang telah dilakukan maka, pada penelitian ini supplier $G$ memiliki nilai $V$ paling tinggi yaitu dengan nilai0.1879, lalu $J$ dengan nilai 0.1694 , selanjutnya $B$ dengan nilai 0.1238 , kemudian C dengan nilai 0.1075, D dengan nilai 0.0924, E dengan nilai 0.0759, A dengan nilai 0.0682, $F$ dengan nilai 0.0630 , I dengan nilai 0.0573 , dan nilai terendah yaitu H dengan nilai 0.0546. Sementara tingkat keberhasilan akurasi metode tersebut sebesar $70 \%$
\end{abstract}

Kata Kunci : Supplier, AHP, Optimalisasi

\section{Pendahuluan}

Strategi yang bisa dilakukan untuk mencapai keunggulan dalam bersaing adalah dengan memperbaiki dalam pemilihan supplier. Pemilihan supplier yang tepat dapat membantu perusahaan untuk mencapai hasil produksi yang diinginkan, sebaliknya jika salah dalam memilih supplier hal tersebut dapat menimbulkan kerugian bagi perusahaan. Dalam hal ini pemilihan supplier berdasarkan penawaran harga yang rendah sudah tidak baik lagi, untuk mendapatkan hasil yang baik perlu menggabungkan kriteria lain yang relevan dengan tujuan perusahaan.

Ada banyak kriteria yang perlu dipertimbangkan dalam pemilihan supplier. Proses pemilihan bisa menjadi sangat kompleks karena suatu supplier bisa saja memiliki sejumlah kemampuan dalam semua kriteria atau kemampuan yang begitu baik hanya pada beberapa kriteria. Beberapa hal yang perlu dipertimbangkan dalam memilih supplier diantaranya kualitas barang yang ditawarkan, pengiriman, harga barang, garansi, dan ketepatan waktu pengiriman.

Pemilihan supplier yang akan digunakan perusahaan merupakan hal yang penting untuk mencapai keunggulan bersaing, karena berkaitan dengan kemampuan memasok dan menyediakan bahan baku yang berkualitas, waktu pengiriman yang singkat, dan kontinuitas produksi.

PT Bakrie Metal Industries (BMI) merupakan perusahaan yang bergerak dalam bidang fabrikasi serta konstruksi besi dan baja di engineering, procurement, construction, and installation (EPCI). Perusahaan yang didirikan pada tahun 1981 ini menghasilkan produk fix 
platform atau fondasi kaki baja di dasar laut untuk dimuati dek dan rig pengeboran minyak dan gas (migas) serta fasilitas produksi dan akomodasi lain untuk eksplorasi migas lepas pantai, jembatan baja, gorong-gorong, conveyor batu bara, mooring tower, nestable flange, multi plate, guard rail, bridge deck, dan steel fabrication.

Maka untuk menghasilkan produk-produk atau mengerjakan proyek tersebut diperlukan pasokan-pasokan dari para supplier agar kegiatan produksi atau proyek dapat berjalan dengan baik. Oleh karena itu, perusahaan dituntut untuk dapat memberikan kepuasan kepada konsumen dalam segala bidang, salah satunya ialah menjaga kualitas produk yang dihasilkan. Pemilihan supplier perlu dilakukan untuk mendapatkan kriteria supplier yang benar-benar mampu memenuhi kebutuhan perusahaan secara konsisten dan berkualitas.

Pemilihan supplier dapat dilakukan dengan beberapa cara salah satunya ialah dengan menggunakan metode Analytical Hierarchy Process (AHP), teori yang dikembangkan oleh Thomas L. Saaty ini dapat digunakan untuk memecahkan masalah yang kompleks, model keputusan ini akan menguraikan masalah multi faktor atau multi kriteria yang kompleks menjadi suatu hierarki. Hierarki didefinisikan sebagai suatu representasi dari sebuah permasalahan yang kompleks dalam suatu struktur multilevel dimana level pertama adalah tujuan, yang diikuti level kriteria, sub kriteria, dan seterusnya ke bawah hingga level terakhir yaitu alternatif.

Penggunaan AHP bukan hanya untuk institusi pemerintahan atau swasta namun juga dapat diaplikasikan untuk keperluan individu terutama untuk penelitian-penelitian yang berkaitan dengan kebijakan atau perumusan strategi prioritas. Mengapa AHP dapat diandalkan, karena dalam AHP suatu prioritas disusun dari berbagai pilihan yang dapat berupa kriteria yang sebelumnya telah didekomposisi terlebih dahulu, sehingga penetapan prioritas didasarkan pada suatu proses yang terstruktur.

AHP juga menguji konsistensi penilaian, konsistensi yang diharapkan adalah yang mendekati sempurna agar menghasilkan keputusan yang valid. Dalam penelitian ini, metode AHP akan digunakan dalam pengambilan keputusan pemilihan supplier guna memberikan supplier yang memenuhi kriteria yang telah ditetapkan perusahaan.

\section{Rumusan Masalah}

Timbulnya permasalahan yang disebabkan oleh supplier berupa kekurangan material, keterlambatan dalam pengiriman atau material yang datang hanya separuh, dan kerusakan barang. Dapat dilihat pada identifikasi masalah di atas, terdapat beberapa contoh permasalahan yang timbul. Berdasarkan tabel di atas dapat diidentifikasikan permasalahan yang ada pada penelitian ini adalah:

a. Kesulitan untuk menentukan bobot prioritas pada setiap supplier.

b. Kesulitan dalam mendapatkan pilihan alternatif supplier.

1. Problem Statement

Dari identifikasi masalah di atas, pernyataan masalah penelitian yang dapat ditetapkan adalah belum optimalnya dalam menentukan supplier pada PT Bakrie Metal Industries. 


\section{Research Question}

Berdasarkan rumusan masalah di atas, pertanyaan penelitian yang dapat diajukan yaitu bagaimana penerapan metode Analytical Hierarcy Process (AHP) untuk optimalisasi penentuan supplier?

\section{Maksud dan Tujuan}

Adapun maksud dari penelitian ini adalah dalam rangka menerapkan metode AHP untuk mengoptimalkan penentuan supplier. Sementara tujuan yang hendak dicapai dari penelitian ini adalah:

1. Menentukan bobot prioritas pada setiap supplier.

2. Mendapatkan alternatif supplier berdasarkan bobot prioritas.

\section{Ruang Lingkup dan Keterbatasan Penelitian}

Adapun ruang lingkup dalam masalah ini adalah sebagai berikut:

1. Penelitian ini dilakukan dengan melihat kondisi permasalahan yang ada pada PT Bakrie Metal Industries.

2. Pemilihan kriteria-kriteria yang menjadi pertimbangan didapatkan berdasarkan observasi dan wawancara.

3. Metode yang digunakan pada penelitian ini adalah AHP.

Sedangkan keterbatasan dalam penelitian ini adalah sebagai berikut:

1. Data supplier yang digunakan merupakan data supplier untukpengadaan material.

2. Kriteria berdasarkan dari hasil dokumentasi perusahaan.

\section{Landasan Teori}

\section{Analytical Hierarchy Process (AHP)}

Menurut Kusrini, (2007, p.133) pada bukunya yang berjudul konsep dan aplikasi sistem pendukung keputusan, menyatakan bahwa proses pengambilan keputusan adalah memilih suatu altematif. AHP adalah metode keputusan multikriteria untuk pemecahan masalah yang kompleks. Peralatan utama AHP adalah sebuah hierarki fungsional dengan input utamanya persepsi manusia.

Metode ini adalah sebuah kerangka untuk mengambil keputusan dengan efektifitas persoalan dengan menyederhanakan dan mempercepat proses pengambilan keputusan dengan memecahkan persoalan tersebut kedalam bagian-bagiannya, menata bagian atau variabel ini dalam suatu susunan hierarki, memberi nilai numerik pada pertimbangan subjektif tentang pentingnya tiap variabel dan mensintesis berbagai pertimbangan ini untuk menetapkan variabel mana yang memiliki prioritas paling tinggi dan bertindak untuk mempengaruhi hasil pada situasi tersebut. Metode ini juga menggabungkan kekuatan dari perasaan dan logika yang bersangkutan pada berbagai persoalan, lalu mensintesis berbagai pertimbangan yang 
beragam menjadi hasil yang cocok dengan perkiraan kita secara intuitif sebagaimana yang dipersentasikan pada pertimbangan yang telah dibuat.

Analytical Hierarchy Process (AHP) dapat menyederhanakan masalah yang kompleks dan tidak terstruktur, strategi, dan dinamik menjadi bagianya, serta menjadikan variabel dalam suatu hierarki (tingkatan). Masalah yang kompleks dapat diartikan bahwa kriteria dari suatu masalah yang begitu banyak (multikriteria), struktur masalah yang belum jelas, ketidakpastian pendapat dari pengambilan keputusan, pengambilan keputusan lebih dari satu orang, serta ketidakakuratan data yang tersedia.

\section{Prinsip Dasar AHP}

Dalam menyelesaikan permasalahan dengan AHP ada beberapa prinsip yang harus dipahami, diantaranya adalah menurut Kusrini, (2007,p.133):

a. Membuat hierarki

Sistem yang kompleks bisa dipahami dengan memecahnya menjadi elemen-elemen pendukung, menyusun elemen secara hierarki, dan menggabungkannya atau mensintesisnya.

b. Penilaian kriteria dan alternatif

Kriteria dan alternatif dilakukan dengan perbandingan berpasangan menurut saaty (1988), untuk berbagai persoalan, skala 1 sampai 9 adalah skala terbaik untuk mengekspresikan pendapat. Nilai dan definisi pendapat kualitatif dari skala perbandingan saaty bisa diukur menggunakan tabel analisis.

c. Menentukan prioritas (Synthesis of priority)

Untuk setiap kriteria dan alternatif, perlu dilakukan perbandingan berpasangan (pairwise comparisons). Nilai-nilai perbandingan relatif dari seluruh alternatif kriteria bisa disesuaikan dengan judgement yang telah ditentukan untuk menghasilkan bobot dan prioritas. Bobot dan prioritas dihitung dengan memanipulasi matriks atau melalui penyelesaian persamaan matematika

d. Konsistensi Logis (Logical Consistency)

Konsistensi memiliki dua makna. Pertama, objek-objek yang serupa bisa dikelompokkan sesuai dengan keseragaman dan relevansi. Kedua, menyangkut tingkat hubungan antar objek yang didasarkan pada kriteria tertentu.

Langkah-langkah dalam metode AHP menurut Kusrini, (2007,p.135) meliputi:

a. Mendefinisikan masalah dan menentukan solusi yang diinginkan, lalu menyusun hierarki dari permasalahan yang dihadapi. Penyusunan hierarki adalah dengan menetapkan tujuan yang merupakan sasaran sistem secara keseluruhan pada level teratas.

b. Menentukan prioritas elemen

1. Langkah pertama dalam menentukan prioritas elemen adalah membuat perbandingan pasangan, yaitu membandingkan elemen secara berpasangan sesuai kriteria yang diberikan. 
2. Matriks perbandingan berpasangan diisi menggunakan bilangan untuk mempresentasikan kepentingan relatif dari suatu elemen terhadap elemen yang lainnya

3. Sintesis

Pertimbangan-pertimbangan terhadap perbandingan berpasangan disintesis untuk memperoleh keseluruhan prioritas. Hal-hal yang dilakukan dalam langkah ini adalah:

(1) Menjumlahkan nilai-nilai dari setiap kolom pada matriks.

(2) Membagi setiap nilai dari kolom dengan total kolom yang bersangkutan untuk memperoleh normalisasi matriks.

(3) Menjumlahkan nilai-nilai dari setiap baris dan membaginya dengan jumlah elemen untuk mendapatkan nilai rata-rata.

c. Mengukur konsistensi

Dalam pembuatan keputusan, penting untuk mengetahui seberapa baik konsistensi yang ada karena kita tidak menginginkan keputusan berdasarkan pertimbangan dengan konsistensi yang rendah. Hal-hal yang dilakukan dalam langkah ini adalah:

1. Kalikan setiap nilai pada kolom pertama dengan prioritas relatif elemen pertama, nilai pada kolom kedua dengan prioritas relatif elemen kedua, dan seterusnya.

2. Jumlahkan setiap baris.

3. Hasil dari penjumlahan baris dibagi dengan elemen prioritas relatif yang bersangkutan.

4. Jumlahkan hasil bagi diatas dengan banyaknya elemen yang ada, hasilnya disebut $\lambda$ maks.

d. Hitung consistency index $(\mathrm{Cl})$ dengan rumus:

$\mathrm{Cl}=(\lambda$ maks $-\mathrm{n}) / \mathrm{n}$

Dimana $\mathrm{n}=$ banyaknya elemen

e. Hitung rasio konsistensi / consistency ratio (CR) dengan rumus:

$\mathrm{CR}=\mathrm{Cl} / \mathrm{IR}$

Dimana $\quad \mathrm{CR}=$ Consistency Ratio

$\mathrm{Cl}=$ Consistensy Index

$\mathrm{IR}=$ Index Random Consistency

f. Memeriksa konsistensi hierarki. Jika nilainya lebih dari $10 \%$, maka penilaian data judgement harus diperbaiki. Namun jika rasio konsistensi (Cl/IR) kurang atau sama dengan 0,1 maka hasil perhitungan bisa dinyatakan benar.

\section{Hasil dan Pembahasan}

\section{Kriteria dan Alternative yang Digunakan}

Dalam menentukan pemilihan supplier ada beberapa variabel yang terlebih dahulu ditentukan yaitu kriteria dan alternatif pemilihan supplier.

1. Kriteria

Merupakan tahapan menentukan ukuran yang menjadi dasar penilaian dalam menentukan supplier, dimana kriteria penilaian yang ditetapkan dalam penellitian ini 
terdiri dari 4 (empat) kriteria. Kriteria pada penelitian ini bersumber dari dokumentasi data perusahaan. Adapun kriteria penentuan supplier ini adalah:
a. Harga
b. Spesifikasi
c. Garansi
d. Waktu

2. Alternatif

Merupakan tahap menentukan pilihan diantara dua atau beberapa kemungkinan yang ada, alternatif dalam pemilihan ini adalah:

Tabel 1. Alternatif Supplier

\begin{tabular}{|c|l|}
\hline Kode Perusahaan & \multicolumn{1}{|c|}{ Alternatif } \\
\hline A & PT. Ciremai Putra Tekindo \\
\hline B & PT. Industira \\
\hline C & PT. Kemenangan \\
\hline D & PT. Kotaminyak Internusa \\
\hline E & PT. Mecotra Permai \\
\hline F & PT. Rulmeca Indonesia \\
\hline G & $\begin{array}{l}\text { PT. Sandvik Mining and } \\
\text { Construction Indonesia }\end{array}$ \\
\hline H & PT. Stomil Indonesia \\
\hline I & PT. Suprabakti Mandiri \\
\hline J & PT. Yasilindo Sinar Pratama \\
\hline
\end{tabular}

Berikut ini merupakan hasil dari perhitungan untuk mencari rasio konsistensi dari kriteria dan setiap alternatif terhadap kriteria:

Tabel 2. Perhitungan Rasio Konsistensi

\begin{tabular}{|c|c|c|c|}
\hline Kriteria & Jumlah & Prioritas & Hasil \\
\hline Harga & 2.3950 & 0.4592 & 2.8542 \\
\hline Spesifikasi & 1.8979 & 0.3284 & 2.2263 \\
\hline Garansi & 0.7787 & 0.1807 & 0.9594 \\
\hline Waktu & 0.1549 & 0.0317 & 0.1866 \\
\hline \multicolumn{3}{|c|}{ Total } & 6.2265 \\
\hline
\end{tabular}

Tabel 3. Perhitungan Rasio Konsistensi Kriteria Harga

\begin{tabular}{|c|c|c|c|}
\hline Alternatif & Jumlah & Prioritas & Hasil \\
\hline A & 1.4892 & 0.0563 & 1.5455 \\
\hline B & 1.9462 & 0.1061 & 2.0523 \\
\hline $\bar{C}$ & 2.8913 & 0.1305 & 3.0218 \\
\hline D & 3.1093 & 0.1375 & 3.2468 \\
\hline$E$ & 1.4402 & 0.0596 & 1.4998 \\
\hline$F$ & 1.2673 & 0.0532 & 1.3205 \\
\hline G & 4.7037 & 0.2155 & 4.9191 \\
\hline $\mathrm{H}$ & 0.8589 & 0.0283 & 0.8873 \\
\hline 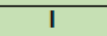 & 1.7214 & 0.0714 & 1.7929 \\
\hline J & 3.3122 & 0.1416 & 3.4537 \\
\hline \multicolumn{3}{|c|}{ Total } & 23.7397 \\
\hline
\end{tabular}


Tabel 4. Perhitungan Rasio Konsistensi Kriteria Spesifikasi

\begin{tabular}{|c|c|c|c|}
\hline Alternatif & Jumlah & Prioritas & Hasil \\
\hline A & 2.0321 & 0.0976 & 2.1297 \\
\hline B & 2.4298 & 0.1238 & 2.5536 \\
\hline C & 1.9992 & 0.0884 & 2.0877 \\
\hline D & 1.4818 & 0.0613 & 1.5431 \\
\hline E & 1.6399 & 0.0659 & 1.7058 \\
\hline F & 1.9605 & 0.0714 & 2.0319 \\
\hline G & 4.2369 & 0.1882 & 4.4251 \\
\hline H & 2.3679 & 0.0872 & 2.4551 \\
\hline I & 1.3718 & 0.0521 & 1.4239 \\
\hline J & 3.2653 & 0.1641 & 3.4295 \\
\hline \multicolumn{4}{|c|}{ Total } \\
\hline \multicolumn{4}{|c}{} \\
\hline
\end{tabular}

Tabel 6. Perhitungan Rasio Konsistensi Kriteria Waktu

\begin{tabular}{|c|c|c|c|}
\hline Alternatif & Jumlah & Prioritas & Hasil \\
\hline A & 2.1349 & 0.1390 & 2.2739 \\
\hline B & 3.0823 & 0.1809 & 3.2632 \\
\hline C & 0.3739 & 0.0331 & 0.4070 \\
\hline D & 2.1604 & 0.1244 & 2.2849 \\
\hline E & 1.5425 & 0.1094 & 1.6519 \\
\hline F & 0.5696 & 0.0471 & 0.6167 \\
\hline G & 2.0681 & 0.1421 & 2.2103 \\
\hline H & 0.2909 & 0.0269 & 0.3178 \\
\hline I & 0.1733 & 0.0134 & 0.1868 \\
\hline J & 2.9977 & 0.1836 & 3.1814 \\
\hline \multicolumn{4}{|c|}{ Total } \\
\hline
\end{tabular}

Tabel 5. Perhitungan Rasio Konsistensi Kriteria Garansi

\begin{tabular}{|c|c|c|c|}
\hline Alternatif & Jumlah & Prioritas & Hasil \\
\hline A & 0.6338 & 0.0325 & 0.6663 \\
\hline B & 3.3180 & 0.1589 & 3.4769 \\
\hline $\mathrm{C}$ & 1.2620 & 0.0971 & 1.3591 \\
\hline D & 0.4731 & 0.0287 & 0.5017 \\
\hline$E$ & 2.7893 & 0.1294 & 2.9187 \\
\hline$F$ & 1.4201 & 0.0753 & 1.4955 \\
\hline G & 2.4424 & 0.1252 & 2.5676 \\
\hline $\mathrm{H}$ & 1.3818 & 0.0669 & 1.4487 \\
\hline$I$ & 0.9735 & 0.0386 & 1.0121 \\
\hline $\mathrm{J}$ & 4.3994 & 0.2474 & 4.6469 \\
\hline \multicolumn{3}{|c|}{ Total } & 20.0934 \\
\hline
\end{tabular}

Berdasarkan penilaian terhadap kriteria dan alternatif yang sudah dilakukan, maka hasilnya dapat dilihat pada tabel di bawah ini.

Tabel 7. Perhitungan Rasio Konsistensi

\begin{tabular}{|l|c|}
\hline \multicolumn{1}{|c|}{ Penilaian } & $\begin{array}{c}\text { Rasio } \\
\text { Konsistensi }\end{array}$ \\
\hline Kriteria & -0.6787 \\
\hline Kriteria harga terhadap alternative & -0.5118 \\
\hline $\begin{array}{l}\text { Kriteria spesifikasiterhadap } \\
\text { alternatif }\end{array}$ & -0.5115 \\
\hline Kriteria garansi terhadap alternatif & -0.5363 \\
\hline Kriteria waktu terhadap altematif & -0.5611 \\
\hline
\end{tabular}


Setelah dilakukan pengujian konsistensi logis yang memenuhi persyaratan yaitu $\mathrm{CR}<$ 0.1 , maka hasil prioritas yang diperoleh dari perhitungan masing-masing kriteria terhadap alternatif dituangkan ke dalam matriks hasil seperti pada tabel di bawah ini.

Tabel 8. Matriks Hasil

\begin{tabular}{|c|c|c|c|c|}
\hline \multirow{2}{*}{ Alternatif } & \multicolumn{4}{|c|}{ Prioritas } \\
\cline { 2 - 5 } & Harga & Spesifikasi & Garansi & Waktu \\
\hline A & 0.0563 & 0.0976 & 0.0325 & 0.1390 \\
\hline B & 0.1061 & 0.1238 & 0.1589 & 0.1809 \\
\hline C & 0.1305 & 0.0884 & 0.0971 & 0.0331 \\
\hline D & 0.1375 & 0.0613 & 0.0287 & 0.1244 \\
\hline E & 0.0596 & 0.0659 & 0.1294 & 0.1094 \\
\hline F & 0.0532 & 0.0714 & 0.0753 & 0.0471 \\
\hline G & 0.2155 & 0.1882 & 0.1252 & 0.1421 \\
\hline H & 0.0283 & 0.0872 & 0.0669 & 0.0269 \\
\hline I & 0.0714 & 0.0521 & 0.0386 & 0.0134 \\
\hline J & 0.1416 & 0.1641 & 0.2474 & 0.1836 \\
\hline
\end{tabular}

Lalu dilakukan pencarian hasil akhir dengan mengalikan nilai masing-masing baris 1 pada tabel 8 dengan nilai baris 1 pada tabel 2perhitungan rasio konsistensi kolom prioritas dan menjumlahkan hasilnya seperti pada contoh sebagai berikut:

$=\left(0.4592^{*} 0.0563\right)+\left(0.3284^{*} 0.0976\right)+\left(0.1807^{\star} 0.0325\right)+\left(0.0317^{*} 0.1390\right)$

$=0.1879$

Lakukan perhitungan yang sama pada baris 2 sampai dengan baris 10 pada tabel 8 dengan nilai baris 2 sampai dengan baris 4 pada tabel 2 sehingga diperoleh hasil seperti tabel di bawah ini.

Tabel 9. Prioritas Hasil

\begin{tabular}{|c|c|}
\hline Alternatif & Nilai \\
\hline G & 0.1879 \\
\hline J & 0.1694 \\
\hline B & 0.1238 \\
\hline C & 0.1075 \\
\hline D & 0.0924 \\
\hline E & 0.0759 \\
\hline A & 0.0682 \\
\hline F & 0.0630 \\
\hline I & 0.0573 \\
\hline H & 0.0546 \\
\hline
\end{tabular}

Dari tabel 9 dapat dijelaskan bahwa G (PT. Sandvik Mining and Construction Indonesia) yang memiliki nilai paling tinggi yaitu dengan nilai 0.1879 , lalu J (PT. Yasilindo Sinar Pratama) dengan nilai 0.1694 , selanjutnya B (PT. Industira) dengan nilai 0.1238 , dilanjutkan dengan C (PT. Kemenangan) dengan nilai 0.1075, D (PT. Kotaminyak Internusa) dengan nilai 0.0924, E 
(PT. Mecotra Permai) dengan nilai 0.0759, A (PT. Ciremai Putra Tekindo) dengan nilai 0.0682, F (PT. Rulmeca Indonesia) dengan nilai 0.0630, I (PT. Suprabakti Mandiri) dengan nilai 0.0573, dan nilai terendah yaitu H (PT. Stomil Indonesia) dengan nilai 0.0546 .

3. Hasil

Metode analisa untuk perbandingan data dari penelitian ini menggunakan metode akurasi, metode akurasi digunakan untuk membandingkan data perusahaan dengan data hasil perhitungan menggunakan metode AHP. Data perusahaan didapatkan dari hasil dokumentasi. Dari hasil perhitungan menggunakan metode AHP dan hasil yang didapat dari perusahaan terdapat 7 perusahaan data pada urutan supplier atau prioritas hasil, sebagaimana yang dapat dilihat pada tabel di bawah ini.

Tabel 10. Perubahan Perbandingan Data

\begin{tabular}{|l|l|}
\hline \multicolumn{1}{|c|}{ Data Perusahaan } & \multicolumn{1}{c|}{ Metode AHP } \\
\hline $\begin{array}{l}\text { PT. Sandvik Mining and } \\
\text { Construction Indonesia }\end{array}$ \\
\hline PT. Mecotra Permai \\
Construction Indonesia
\end{tabular}

Dengan menggunakan rumus berikut maka dilakukan perhitungan untuk mendapatkan akurasi:

$$
\text { Akurasi }=\frac{\text { Jumlah yang diklasifikasi secara benar }}{\text { Total sampel testing yang diuji }}
$$

$$
\begin{aligned}
& \text { Akurasi }=7: 10 \\
& =0.7 * 100 \\
& =70 \%
\end{aligned}
$$

Berdasarkan hasil uji akurasi diketahui bahwa perhitungan dengan menggunakan metode AHP mendapatkan nilai keberhasilan $70 \%$.

\section{Kesimpulan dan Saran}

\section{Kesimpulan}

Berdasarkan hasil penelitian yang telah dilakukan maka dapat disimpulkan bahwa:

1. Dari hasil penelitian yang telah dilakukan dengan metode AHP, menunjukkan bahwa kriteria harga merupakan kriteria yang paling penting dengan nilai 0.4592 , berikutnya 
ialah kriteria spesifikasi dengan nilai 0.3284 , kemudian kriteria garansi dengan nilai 0.1807 , dan kriteria waktu dengan nilai 0.0317 .

2. Untuk mempermudah pemilihan supplier sehingga dapat dihasilkan rekomendasi supplier yang qualified. Maka digunakan pendekatan metode seleksi yang terstruktur, sistematis, dan dapat dipertanggungjawabkan yaitu dengan metode AHP. Dari hasil perhitungan total ranking / prioritas dengan mempertimbangkan 4 kriteria dengan ke10 alternatif. Rekomendasi yang bisa dijadikan rekanan bisnis sebagai supplier adalah G (PT. Sandvik Mining and Construction Indonesia) dengan nilai 0.1879, J (PT. Yasilindo Sinar Pratama) dengan nilai 0.1694, B (PT. Industira) dengan nilai 0.1238, C (PT. Kemenangan) dengan nilai 0.1075, D (PT. Kotaminyak Internusa) dengan nilai 0.0924, E (PT. Mecotra Permai) dengan nilai 0.0759, A (PT. Ciremai Putra Tekindo) dengan nilai 0.0682, F (PT. Rulmeca Indonesia) dengan nilai 0.0630, I (PT. Suprabakti Mandiri) dengan nilai 0.0573 , dan H (PT. Stomil Indonesia) dengan nilai 0.0546 .

Pembuktian sudah dapat dinyatakan akurat, dikarenakan hasil yang didapat dari analisa data bernilai $70 \%$.

\section{Saran}

Dari hasil penelitian ini, penulis menyampaikan saran terhadap penelitian selanjutnya yaitu:

1. Pengembangan penelitian kedepan diharapkan tidak terbatas hanya untuk pengadaan material saja, sehingga diharapkan mampu meningkatkan pemilihan supplier yang lebih optimal di semua jenis supplier.

2. Bagi penelitian selanjutnya diharapkan dapat menambah jumlah sampel atau kriteria dalam penelitian, sehingga diharapkan dapat meningkatkan keakuratan hasil penelitian.

\section{Daftar Pustaka}

Andika, D., Anggraeni, S. K., \& Sirajuddin. (2013). Usulan Pemilihan Supplier Bahan Baku Tetap Menggunakan Vendor Performance Indicator dan Analytical Hierarchy Process ( AHP ). Jurnal Teknik Industri, 1(2), 128-132.

Industri, J. T., Teknik, F., \& Andalas, U. (2015). Analisis Pemilihan Pemasok Dengan Metode Analitycal Hierarcy Process Di Proyek Indarung VI PT Semen Padang. Jurnal Laporan Kerja Praktek, 14(1), 50-65.

Kusrini. 2007. Konsep dan Aplikasi Sistem Pendukung Keputusan. Andi, Yogyakarta. 
Lasakar, M. L. (2014). Pemilihan Supplier Bahan Baku Tinta Dengan Metode Analytical Hierarchy Process (AHP) Pada CV Unitech Indonesia - Semarang. Jurnal IImiah Mahasiswa Universitas Surabaya, 3(2), 1-18.

Limansantoso, M. F. (2013). Pemilihan Supplier Produk Calista Dengan Metode Analytical Hierarchy Process (AHP) Pada PT. Buana Tirta Utama - Gresik. Jurnal IImiah Mahasiswa Universitas Surabaya, 2(1), 1-20.

Mardhikawarih, D. A., Jauhari, W. A., \& Rosyidi, C. N. (2012). Pemilihan Pemasok Drum Pelumas Industri Menggunakan Fuzzy Analytical Hierarchy Process (Studi Kasus: PT. Pertamina Pusat dan Production Unit Gresik). Performa, 11(1), 67-74.

Marimin, Maghfiroh Nurul. 2010. Aplikasi Teknik Pengambilan Keputusan dalam Manajemen Rantai Pasok. PT Penerbit IPB Press, Bogor.

Nurhalimah. (2015). Sistem Pendukung Keputusan Pemilihan Bahan Baku Konveksi Dengan Metode AHP (Studi Kasus: Alta Moda Convection Medan). Informasi Dan Teknologi IImiah (INTI), V(1), 129-136.

Prasetyo Eko. 2014. DATA MINING - Mengolah data menjadi informasi menggunakan matlab. Andi, Yogyakarta.

http://www.informasi-pendidikan.com/2013/08/penjelasan-mengenai-sumber-data.html [diakses 15-09-2015] http://www.rumusstatistik.com/2013/07/varian-dan-standar-deviasi-simpangan.html [diakses 18-09-2015] http://vebryexa.com/kelebihan-dan-kekurangan-analytic-hierarchy-process-ahp.html [diakses 29-09-2015] http://www.pengertianpengertian.com/2011/10/pengertian-dokumentasi.html [diakses 27-10-2015] http://kbbi.web.id/kuesioner [diakses 27-10-2015] 